\title{
REFLEXÕES SOBRE O TERRITÓRIO E A DINÂMICA POPULACIONAL DE IBIRATAIA - BAHIA
}

\author{
Reflections on the territory and the population dynamics of Ibirataia - Bahia
}

Jorman dos Santos ${ }^{1}$ http://orcid.org/0000-0003-0705-7774

${ }^{1}$ Mestrando em Geografia pelo Programa de Pós-Graduação da UESB - Bahia-Brasil, email - jormansantos@ gmail.com.

\begin{abstract}
Resumo
A natureza dos fluxos migratórios na contemporaneidade são as mais variadas possíveis. Qualquer processo de formação territorial está intimamente ligado a esses movimentos, inclusive à busca de espaços de maior dinamismo econômico. A partir do alicerce contido nessas afirmações, buscou-se analisar Ibirataia, enquanto cidade pequena por meio de sua caracterização demográfica e pela sua diversificação territorial, tendo como base, uma conceituação do termo migração, do seu contexto na dinâmica populacional e de sua influencia na dinâmica do território. Foi elaborada uma analise mais ampla, na qual se discute a importância dos fluxos migratórios para o processo de desenvolvimento da humanidade, seguindo para uma análise dos movimentos populacionais no Brasil e na Bahia, produzindo posteriormente um diagnóstico específico dos fluxos da mobilidade de pessoas no território que envolve Ibirataia e sua microrregião.
\end{abstract}

Palavras-chave: Território, Dinâmica Populacional, Cidade Pequena.

\begin{abstract}
The nature of migratory flows in contemporary times is as varied as possible. Any process of territorial formation is closely linked to these movements, including the search for spaces of greater economic dynamism. Based on the foundation contained in these statements, we sought to analyze Ibirataia, as a small city through its demographic characterization and its territorial diversification, based on a conceptualization of the term migration, its context in population dynamics and its influence on dynamics of the territory. A broader analysis was elaborated, in which the importance of migratory flows for the development process of humanity is discussed, followed for an analysis of the population movements in Brazil and Bahia, producing later a specific diagnosis of the flows of the mobility of people in the territory which involves Ibirataia and your microregion.
\end{abstract}

Keywords: Territory, Population Dynamics, Small Town.

\section{Introdução}


Os deslocamentos humanos contribuem para as transformações dos espaços geográficos, pois são responsáveis por povoamentos, miscigenação e muitas vezes, alterações nas bases dos sistemas produtivos. Dessa forma não se pode entender a dinâmica populacional isolada das demais relações sociais, ou seja, como uma parte desligada do todo. Pois não se trata apenas de números, análises estatísticas, mas, sim de homens concretos, seres reais que na luta pela sobrevivência são compelidos a mudanças geográficas.

Muitos são os fatores que contribuem para os movimentos migratórios, a História registra grandes fluxos em diversas épocas, motivadas por causas sociais, econômicas, religiosas, políticas e naturais, a exemplo de secas, terremotos e outros flagelos. Contudo, de todas as causas, a econômica é a mais destacada principalmente no modo de produção capitalista, pois tem a capacidade de direcionar o homem na busca das regiões ou locais de maior dinamismo econômico.

A relevância do estudo sobre os movimentos migratórios em um município se dá pela própria importância de reconhecer o espaço urbano desses municípios como áreas não apenas formadas por aglomerações de pessoas, mas ambientes onde esses contingentes populacionais constroem suas histórias, através do trabalho, da habitação, do estudo e do próprio lazer. Existe em cada cidade uma rede de relações que se estabelece e se transforma diariamente entre os seus habitantes, e destes com os habitantes do campo e com os habitantes de outras cidades, em busca de negócios e da utilização de serviços.

Mendes Costa (2012) chama a atenção para a importância de se debater os problemas que afetam uma comunidade, e de como o reconhecimento da natureza desses problemas poderia ajudar a construir soluções que pudessem beneficiar toda uma sociedade. Segundo o autor:

É de se inferir ainda que a inexistência de Redes de Interesses para debater permanentemente os problemas e as aflições da comunidade regional pode ter sido o fio causador da perda de poder da Região, pois um povo que não se une e se aliança para discutir as próprias relações não aprende a reivindicar soluções da sua problemática, ficando fadado ao ocaso e à própria sucumbência. (MENDES COSTA, 2012, p. 226).

Contudo, além de compreender as razões que levaram o surgimento de um determinado problema e seus impactos na sociedade, é necessária também uma 
caracterização do espaço de influência desse acontecimento, pois, a bem da verdade é nesse ambiente coletivo onde se desenrola toda a história de construção e reconstrução das relações sociais.

Dentre vários exemplos desta influência econômica nos fluxos migratórios temse o município de Ibirataia localizado na microrregião Ilhéus-Itabuna. De acordo com o IBGE, o censo de 2010 revelou uma população de 18.943 habitantes apresentando posteriormente estimativa de redução populacional para os anos de 2013 e 2014. O município que atualmente apresenta no setor de serviços o principal componente do seu PIB parece assistir passivamente a saída de fatia de sua população, sobretudo de jovens, para outras cidades em busca de melhores oportunidades, o que muitas vezes reflete a falta de uma infraestrutura adequada que possibilite ao morador local usufruir de boa qualidade de vida sem a necessidade de sair de sua cidade natal. Para Santos e Silveira (2003),

Num mundo onde a fluidez é indispensável às atividades mais poderosas e a gama de produções presentes num lugar se diferencia também por suas exigências de infra-estrutura modernizada e pela necessidade de fluidez, uma relação se estabelece, no conjunto do organismo urbano, entre uma tipologia de sistemas de engenharia e uma tipologia de níveis de modernidade na produção, no emprego, na circulação, na distribuição e no consumo. (SANTOS; SILVEIRA 2003, p. 283).

Buscando apresentar algumas características do espaço urbano de Ibirataia, o artigo realiza uma caracterização demográfica do município, a partir de dados secundários do IBGE e outras fontes para compreender o perfil das migrações que ocorrem no município, verificando como o saldo migratório negativo pode interferir na organização e aplicação de políticas públicas, além de relacionar o contexto histórico e geográfico do município com o contexto da sua microrregião e também do estado da Bahia.

O estudo pode ainda servir de instrumento importante para a administração pública, fornecendo informações que sirvam de base aos mecanismos de governança, permitindo uma gestão mais eficiente, que desenvolva ações equitativas e transparentes. Através da implantação de políticas públicas capazes de garantir a população local um projeto de desenvolvimento mais humano e mais justo, sobretudo para os jovens, que são os que mais buscam a saída do município. 


\title{
A importância da análise demográfica e da mobilidade das pessoas em cidades pequenas
}

A importância do estudo da população está relacionada com a necessidade de compreensão dos inúmeros fenômenos que envolvem a dinâmica populacional e sua atuação sobre o território, ou seja, compreender sua estrutura ou composição etária, a análise das taxas de crescimento vegetativo, pois dependendo do perfil predominante num determinado espaço, a situação econômico-social tem relação direta com essa característica. Entretanto a pesquisa empregará maior análise no estudo dos movimentos populacionais, ou seja, analisando o jogo de relações e inter-relações que envolvem os movimentos migratórios. Assim,

\begin{abstract}
A decisão de migrar de pequenos centros ou de zonas rurais para cidades maiores passa por diversos fatores que terminam convergindo para a efetivação do fato em si. O anseio individual pela modernidade, as necessidades econômicas, o desemprego são fatores que reforçam as decisões de mudança, muitas vezes, apresentando-se como fatores de expulsão de determinados espaços (SANTOS, 2014, p.2).
\end{abstract}

Atualmente, no mundo cada vez mais globalizado e marcado pela aceleração dos fluxos econômicos, de informação, de mercadoria e, sobretudo de pessoas, tem se buscado a realização de estudos que discutam a relação direta e indireta desses fluxos com a sociedade. Historicamente, as migrações sempre tenderam a ocorrer das áreas de maior necessidade econômica e social para as áreas mais desenvolvidas, gerando impactos tanto nos locais de repulsão, quanto nos locais de atração populacional, fenômenos como a xenofobia, favelização, violência e até o aumento dos impactos ambientais, tem suas raízes ligadas a esse processo.

No Brasil, a história dos movimentos migratórios se confunde com a própria história do país, no contexto desses fluxos populacionais no território nacional, destacam-se inúmeros grupos étnicos como os negros africanos vindos de forma forçada a partir do século XVII, europeus principalmente a partir da segunda metade do século XIX para substituir a mão de obra escrava, além de outros grupos como japoneses e árabes. Na análise de Santos e Silveira (2008, p. 212), "a partir de 1950 verifica-se uma aceleração do movimento migratório no país e tanto as taxas de emigração líquida como as de imigração líquida conhecem uma evolução positiva".

Desde o período colonial, as atividades ligadas ao setor primário contribuíram significativamente para impulsionar os movimentos migratórios no Brasil, a implantação de um modelo agrícola pautado na monocultura em grandes propriedades 
sempre predominou na maior parte do território, o que exigia uma numerosa mão de obra que fosse capaz de sustentar esse modelo. A partir do século XX, no entanto, a industrialização e a posterior mecanização agrícola, contribuíram para um intenso processo de êxodo rural. Segundo Scarlato,

A ampliação das relações capitalistas no campo, desestruturando as antigas relações tradicionais de trabalho (a parceria, o arrendamento etc.), a mecanização da agricultura, a substituição da lavoura por pastos e a grande especulação imobiliária foram causas que estimularam a fuga da população do campo para as cidades. (SCARLATO, 1996, p.393).

Dessa forma o quadro de desigualdade estabelecido no campo brasileiro, por conta da má distribuição de terras, contribuiu para que muitas famílias migrassem de um local para outro em busca de trabalho. Além disso, à implantação de culturas sazonais em muitas propriedades foi responsável por produzir movimentos migratórios não definitivos onde os trabalhadores se deslocavam do seu local de origem no período da safra em direção ao local da colheita (geralmente cana-de-açúcar, café, laranja, entre outros.). Assim segundo Dowbor,

Tratar-se-ia de um verdadeiro "nomadismo profissional", referindo-se aos deslocamentos de mão-de-obra agrícola graças à expansão da mecanização e da pecuária, mas também às necessidades de mão-deobra estacional em lavouras como a de cana-de-açúcar e em culturas modernas. (DOWBOR 1986, apud SANTOS; SILVEIRA, 2003, p. 213).

A mecanização acelerada em algumas áreas do campo no Brasil, a partir da década de 1980, também produziu movimentos migratórios importantes, sobretudo em áreas onde se estabeleciam outrora atividades tradicionais com pouca ou nenhuma mecanização. Num curto espaço de tempo os trabalhadores que viviam nessas áreas passam a ser substituídos pelas máquinas, ou seja, a inserção de tecnologias modernas no campo contribuiu para acelerar o êxodo rural no Brasil.

Eis o que Santos e Silveira (2008), com muita precisão, diz a respeito:

Em 1980, 11,5 milhões de famílias não dispunham de Terra ou já não sobreviviam em pequenas propriedades. Isso significa que um terço da população, cerca de 40 milhões de pessoas, estava em permanente migração, tentando fixar-se no campo, mas frequentemente não o conseguindo. É um novo patamar do êxodo rural, devido a uma combinação explosiva de uma estrutura fundiária arcaica em zonas agrícolas tradicionais e da modernização capitalista do campo em zonas dinâmicas e em áreas de colonização agrícola e de produção recente. (SANTOS; SILVEIRA, 2008, p. 213). 
A falta de um planejamento e de políticas públicas que garantissem a população recém-chegada do campo oferta de trabalho, moradia, segurança, alimentação, entre outros, fez com que aumentasse demasiadamente o número de novos municípios no Brasil nesse período, a zona urbana passa a ser mais atrativa aos olhos da população, a rede urbana brasileira começa a se estruturar de acordo com os interesses do capital e ao mesmo tempo surge uma série de problemas urbanos, tais como violência, favelização, desemprego estrutural entre outros.

As cidades brasileiras, principalmente nas últimas décadas do século $\mathrm{XX}$, passam a refletir em seus territórios os reflexos nocivos da urbanização acelerada, provocada pela explosão da migração rural-urbana, as periferias crescem num ritmo desenfreado no conjunto tempo/espaço e de acordo com Oliveira (2009, p. 160) "Simultaneamente, aumentam os reclamos dos mais pobres por habitação, saúde, educação e trabalho, requisitos essenciais à realização da vida". Ou seja, crescimento urbano nem sempre significa melhor qualidade de vida, pelo menos para uma parcela significativa da sociedade.

Oliveira (2009) propõe uma análise e uma construção de políticas públicas em longo prazo, mas buscando compreender as reais necessidades do presente, a fim de que se possa planejar um futuro melhor para a cidade e seus habitantes. Segundo a autora:

A cidade que temos hoje pode servir de parâmetro para projetarmos a cidade do futuro. As decisões que forem tomadas agora coletivamente - implicarão no tipo de cidade (e de cidadão) que teremos em breve. Isto serve para São Paulo, Itabuna ou Camacan. É preciso que as coletividades se envolvam de fato com as questões municipais. É preciso construir instrumentos democráticos que incentivem e permitam a participação popular quanto aos destinos da cidade. (OLIVEIRA, 2009, p.160).

O planejamento urbano deve ser pensado, visando atingir os interesses da coletividade, e não apenas de um pequeno grupo como tem acontecido na grande maioria dos municípios no Brasil, mas, sobretudo é preciso entender a cidade como um espaço dinâmico, onde os movimentos migratórios internos ou externos constituem ferramenta importante na formação e transformação do espaço. 


\section{A dinâmica do território e da população de Ibirataia no contexto da região Sul da Bahia}

Desde meados do século XIX, o Sul da Bahia na qual está inserida a cidade de Ibirataia convive com intensos fluxos migratórios, motivados principalmente pela cacauicultura; a história revela tratar-se de uma região cuja dinâmica econômica, política e social, desde o princípio, esteve fortemente atrelada à atividade cacaueira (SANTOS, 2012, p. 23). Contudo os fluxos migratórios não são formados apenas por fatores atrativos que funcionam como estímulos a vinda de imigrantes, mas também envolvem fatores repulsivos tais como secas e estagnação econômica nos locais de origem desses imigrantes.

Figura1- Mapa da Microrregião Sul da Bahia

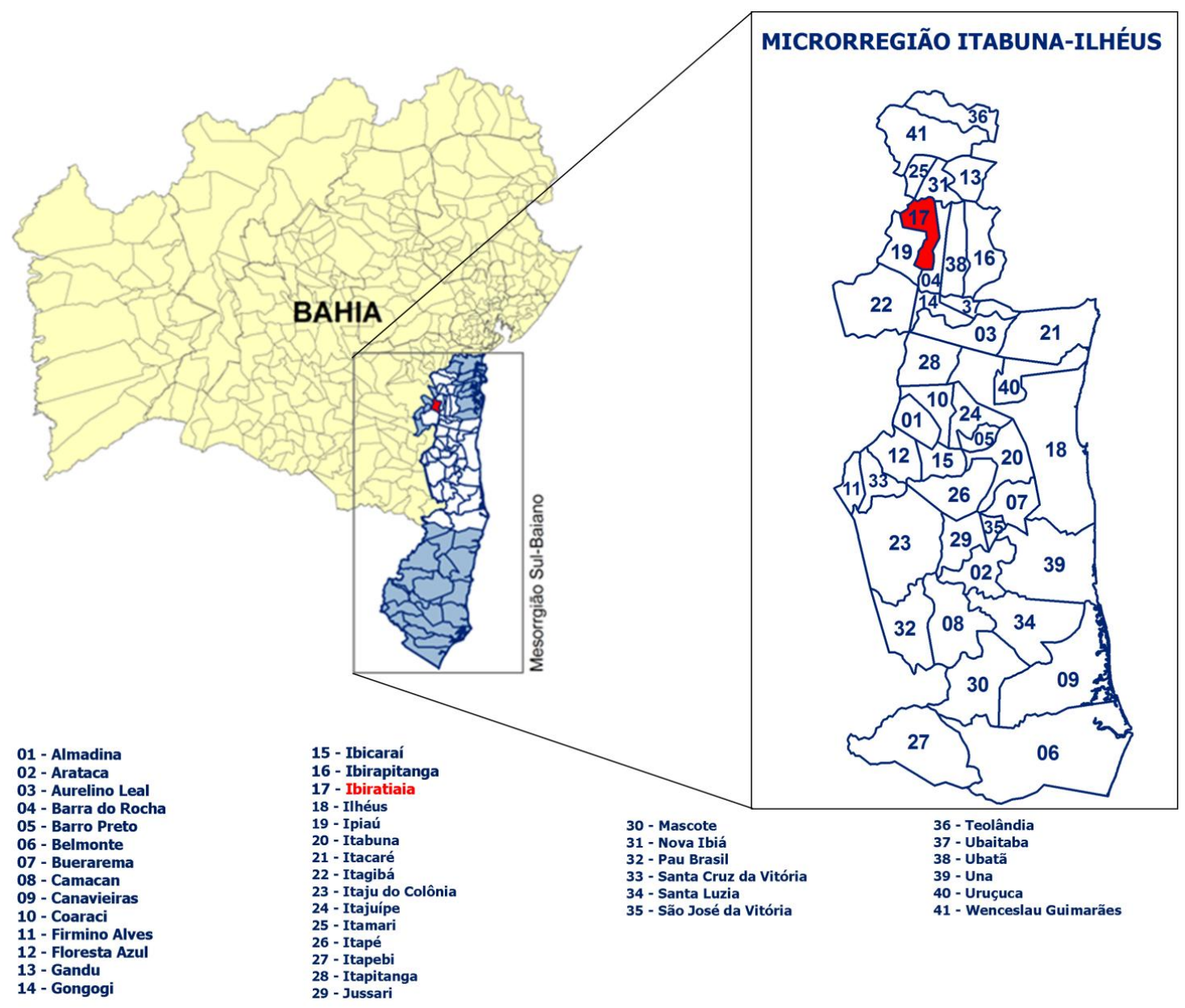

Fonte: Adaptado do IBGE, 2014. 
Durante o processo de formação e Expansão da Lavoura Cacaueira, por exemplo, entre o final do século XVIII e início do XIX, que visava à recomposição econômica da capitania de Ilhéus, essa onda migratória fica evidente, pois:

Como a exploração da terra voltada para a cacauicultura era fruto da saga aventureira dos desbravadores objetivando tirar proveitos econômicos mais abundantes, eles preferiam se aventurar com familiares ou poucos aliados para conquistar áreas mais férteis e espalhar as sementes do "fruto de ouro". MENDES COSTA, (2012, p. 22).

A chegada do cacau contribuiu bastante para o processo de ocupação e povoamento da região Sul da Bahia, tendo em vista que essa atividade econômica fez com que a região tornasse uma grande área de atração populacional, recebendo migrantes de diversos locais, sobretudo de estados nordestinos assolados pela seca ou pelo declínio da atividade açucareira. Dessa forma a população que chegava ao sul da Bahia, trazia consigo hábitos, crenças e costumes que contribuíram para a formação da civilização cacaueira, sendo personagens do processo de desenvolvimento econômico pelo qual passou a região.

O cacau também possibilitou que o sul da Bahia tornasse conhecido nacional e internacionalmente, principalmente por conta da grande aceitação do produto no mercado internacional, sobretudo o europeu, a boa produção agrícola da região proporcionava grande oferta de trabalho, ainda que mal remunerada, onde, por exemplo, numa única fazenda de porte médio havia dezenas de famílias vivendo em torno da produção cacaueira. De acordo com Rocha,

Nos anos 1930 alcançara o status de região rica, onde o comando político e econômico era exercido pelos coronéis do cacau, servidos pelos jagunços e trabalhadores rurais. Esta década caracterizou-se pela conquista da terra, sendo o cacau o produto em torno do qual girava a economia e a dinâmica social. A identidade da terra do cacau era composta pela força do fazendeiro, pela submissão e ignorância do trabalhador rural, pelos jagunços, meretrizes, com seus costumes, crendices e superstições. (ROCHA, 2003, p. 44).

Associado ao desenvolvimento da atividade agrícola e ao posterior incremento das atividades comerciais passa a ser formada na região uma rede de fluxos muito intensa entre os novos núcleos de povoamento, que se expandem espacialmente e passam a adquirir o status de cidades em um meio eminentemente rural. Dessa forma, a 
partir da segunda metade do século $\mathrm{XX}$, ocorre o surgimento de novas cidades, ofertando serviços ligados direta e indiretamente a cultura cacaueira. Assim,

Os efeitos positivos da cacauicultura são demonstrados pela sua capacidade de absorção e mão de obra aplicada na lavoura, representando $1 / 4$ da população regional diretamente utilizada com os trabalhos do cacau no meio rural. No período 1970-1990, o sul da Bahia viveu em pleno emprego, demonstrando o potencial multiplicador da cacauicultura pela absorção da população em atividades ocupacionais extensivas ao cultivo. (MENDES COSTA, 2012, p. 218).

Contudo com a crise da vassoura-de-bruxa que atinge a região no final da década de 1980 força uma mudança radical no sentido das migrações, ou seja, a região cacaueira que outrora se caracterizava como uma região de forte atração populacional passa agora a ser identificada como uma região de repulsão populacional. Além das perdas demográficas, a região passa a enfrentar também perdas econômicas sucessivas, repercutindo significativamente na organização social do espaço.

Um novo cenário passa a ser desenhado com o advento da vassoura-de-bruxa, uma nova e assustadora realidade se apresenta para a população da região, sendo quase impossível apresentar algum setor ou segmento da sociedade que não tenha sido atingido pela crise, corte de salários, desemprego, queda no PIB, migrações, entre outros, foram consequência direta dessa nova realidade. Segundo Rocha (2003. p 55), como se fosse um efeito dominó, todas as classes sociais foram atingidas, trazendo recessão na articulação de dinheiro e investimentos.

A denominação "Região Cacaueira da Bahia" passa a não representar mais plenamente as características que envolvem os municípios e a civilização local, dessa forma novas formas de classificação desse recorte espacial irão surgir, tais como: Região Sul da Bahia, Microrregião Ilhéus-Itabuna, entre outras, buscando não apagar o legado que a cacauicultura criou na região, mas na tentativa de tentar representar também as novas forças econômicas, sociais e políticas que atuam no processo de redefinição das características desse território.

Sobre essa nova etapa a ser enfrentada por toda a população, Rocha (2003) faz uma análise acerca da situação socioeconômica e cita alguns caminhos que se tem buscado para o enfrentamento da crise, afirmando, 
A população regional, como um todo, empobreceu. É claro que, antes disso, "havia pobreza, como em todo o mundo, mas não havia miséria. Já foi-se o tempo áureo, os cacauais foram atacados pela praga que veio da Amazônia, os preços despencaram e as cobiçadas fazendas perderam o seu valor. $O$ desemprego na zona rural aumentou, o inchaço na periferia da cidade também cresceu, e temos um cinturão de miséria assaz preocupante" (Jornal Agora, 28 de julho a 5 de agosto de 1995, caderno 3, p. 2, apud ROCHA, 2003, p. 56).

De acordo com a caracterização da crise econômica exposta acima, seria quase inevitável que um fluxo emigratório não atingisse a região, mas da mesma forma a busca pelo desenvolvimento de novas atividades econômicas, como forma de vencer a crise, também passaram a fazer parte do cotidiano da população que ainda permanece na região. Tudo isso em meio a uma rede urbana ainda em construção, compostas por cidades que em sua grande maioria tem no seu processo histórico de formação bastante semelhança.

A tabela 1 sintetiza, pelo menos em números absolutos, uma distribuição desigual da população pelo território da microrregião, de acordo com os dados nela contidos, em apenas 2 municípios estão concentrados quase $40 \%$ da população local, o que caracteriza uma rede urbana onde as ofertas de serviços mais diversificados e importantes, estão concentrados em poucos espaços.

Tabela 1: Microrregião Itabuna-Ilhéus: número de municípios por tamanho populacional

\begin{tabular}{|c|c|c|c|c|}
\hline \multirow{2}{*}{$\begin{array}{l}\text { CLASSE DE TAMANHO } \\
\text { Hab./Município }\end{array}$} & \multicolumn{2}{|c|}{ MUNICÍPIOS } & \multicolumn{2}{|c|}{ POPULAC̄̃̃O TOTAL } \\
\hline & $\mathbf{N}^{\mathbf{o}}$ & $\%$ & $\mathbf{N}^{\mathbf{o}}$ & $\%$ \\
\hline Menos de 10.000 & 11 & 26,82 & 73.586 & 7,21 \\
\hline De 10.001 a 20.000 & 14 & 34,15 & 192.594 & 18,87 \\
\hline De 20.001 a 40.000 & 13 & 31,71 & 321.169 & 31,46 \\
\hline De 40.001 a 100.000 & 1 & 2,44 & 44.390 & 4,35 \\
\hline De 100.001 a 200.000 & 1 & 2,44 & 184.236 & 18,06 \\
\hline Mais de 200.000 & 1 & 2,44 & 204.667 & 20,05 \\
\hline TOTAL & 41 & 100,00 & 1.020 .642 & 100,00 \\
\hline
\end{tabular}

Fonte: IBGE - Censo Demográfico 2010.

Apenas dois municípios na microrregião têm mais de 100 mil habitantes: Ilhéus e Itabuna, segundo dados do IBGE (2010). Do total, 25 municípios (60,9\%) têm até 20 mil habitantes (o município de Ibirataia está inserido nesta categoria), 13 (31,7\%) têm 
entre 20.001 e 40.000 habitantes e somente um município situa-se na faixa entre 40.001 e 100.000 habitantes: Ipiaú (44.390).

Ibirataia ocupa uma área territorial de $294,865 \mathrm{~km}^{2}$ e conta atualmente com uma população de 18.943 habitantes (Tabela 2); sua taxa de urbanização é superior a 83\%, segundo dados do IBGE (2010). Insere-se entre as cidades pequenas do interior baiano, ocupando o correspondente a $0,1 \%$ da população do Estado da Bahia.

Tabela 2: Evolução Populacional do município, estado e país 1991 a 2010.

\begin{tabular}{l|l|l|l}
\hline Ano & Ibirataia & Bahia & Brasil \\
\hline 1991 & 22.694 & 11.867 .991 & 146.825 .475 \\
\hline 1996 & 25.420 & 12.472 .894 & 156.032 .944 \\
\hline 2000 & 24.741 & 13.070 .250 & 169.799 .170 \\
\hline 2007 & 23.940 & 14.080 .654 & 183.987 .291 \\
\hline 2010 & 18.943 & 14.016 .906 & 190.755 .799 \\
\hline
\end{tabular}

Fonte: IBGE, 2010

Conforme os dados da tabela 2 percebe-se que o município de Ibirataia vem perdendo população gradativamente nos últimos anos, sobretudo a população rural do município e também na região cacaueira. A queda da produção de cacau contribuiu para que a fragilidade do modelo monocultor ficasse evidente, pois toda a cadeia produtiva instalada a décadas na região, não se mostrou capaz de enfrentar a Vassoura-De-Bruxa e evitar a saída em massa da população local para outras áreas do estado e do país.

De acordo com Mendes Costa (2012, p. 105):

A dependência do desenvolvimento dos agentes econômicos privados se revelou ainda mais grave nas áreas rurais, onde o setor privado era o principal responsável pela modernização da agricultura das últimas décadas e onde, por outro lado, a presença do Estado como agente de modernização, sobretudo através da prestação dos serviços públicos à população rural, era bastante limitada.

A trajetória têmporo-espacial de Ibirataia no contexto da Microrregião Itabuna-Ilhéus é relativamente recente. São pouco mais de cinco décadas de territorialização da cidade, de construção de uma paisagem urbana com forte conteúdo de ruralidade. Trindade (2011), afirma que a rede urbana do sul da Bahia, não pode ser analisada em separado da rede urbana brasileira, pois constitui parte integrante da mesma, reproduzindo regionalmente, algumas características que são comuns a grande parte do território brasileiro. Assim, 
A consideração do tempo histórico é fundamental para se compreender muita das assimetrias existentes entre essas cidades nos dias de hoje; desde diferenças quanto à estrutura intra-urbana, aos aspectos econômicos e demográficos, e mesmo quanto às funções que exercem regionalmente. (TRINDADE, 2011, p. 165).

A cidade é, pois nesse sentido, um ambiente permanente de construção e reconstrução do espaço, ou seja, da mesma forma que existe uma ideologia por parte do poder econômico de busca constante pela homogeneização do espaço, a fim de garantir maiores lucros e uma reprodução continua do capital, há também uma interação entre as cidades, seus habitantes e as funções próprias de cada espaço dentro de uma rede urbana, o que acaba por promover as especificidades de cada lugar.

\section{Aspectos populacionais e configuração socioespacial de Ibirataia}

A população de Ibirataia evoluiu de forma lenta e gradual, ao longo dessas cinco décadas de constituição do município. O fator principal a assegurar o seu crescimento foi a atividade cacaueira, não obstante, é o declínio dessa atividade, no final dos anos 80, que explica a alteração do seu ritmo de crescimento e as perdas significativas de contingente populacional. De acordo com os cinco últimos levantamentos censitários realizados pelo IBGE, Ibirataia inclui-se entre os municípios baianos que registraram perda de população entre 2000/2010. Dentre esses municípios, encontram-se muitos que, como Ibirataia, estão localizados na Microrregião Itabuna-Ilhéus.

Tabela 3 - População residente: urbana - rural e total; taxa de urbanização e área territorial do Município de Ibirataia (1970-2010)

\begin{tabular}{|c|c|c|c|c|c|c|}
\hline Ano & Urbana & Rural & Total & $\begin{array}{ll}\text { Taxa } & \text { de } \\
\text { urbanização }\end{array}$ & $\begin{array}{l}\text { Área } \\
\left(\mathbf{k m}^{2}\right)\end{array}$ & $\begin{array}{l}\text { Densidade } \\
\text { demográfica } \\
\left(\mathbf{h a b} / \mathbf{m}^{2}\right)\end{array}$ \\
\hline 1970 & 6.070 & 8.358 & 14.428 & $42,07 \%$ & 294,865 & 48,93 \\
\hline 1980 & 9.999 & 9.978 & 19.977 & $50,05 \%$ & 294,865 & 67,76 \\
\hline 1991 & 15.369 & 7.325 & 22.694 & $67,72 \%$ & 294,865 & 76,96 \\
\hline 2000 & 18.726 & 6.015 & 24.741 & $75,69 \%$ & 294,865 & 83,90 \\
\hline 2010 & 15.742 & 3.201 & 18.943 & $83,10 \%$ & 294,865 & 64,24 \\
\hline
\end{tabular}

Fonte: IBGE - Censos Demográficos, 1970 a 2010 
Apesar de apresentar crescimento positivo entre 1991 e 2000 de acordo com os dados da Tabela 3, Ibirataia perde na década seguinte entre 2000 e 2010, praticamente 1/4 de sua população. Muitos elementos compõem o cenário que permite compreender melhor as razões dessas saídas, tais como a falta de uma infra-estrutura moderna, a perda de capital por conta da crise da lavoura cacaueira, a baixa oferta de emprego entre outros. Por outro lado mesmo com a perda de população na última década, vale ressaltar que Ibirataia, no âmbito da Microrregião Itabuna-Ilhéus, está entre os 15 municípios cujos graus de urbanização em 2010 situam-se acima de 80\%. Naquele ano, registrou-se que $83,10 \%$ da população do município viviam em espaços considerados, oficialmente, como urbanos - a sede e os distritos.

Os dados da Tabela 3 confirmam o crescimento continuado da população urbana do município, que passou de 6.070, na década de 1970, para 15.742 habitantes, em 2010, um aumento superior a 159\%. Tal como no Estado da Bahia, foi somente na década de 1980, de acordo com dados do IBGE, que a concentração da população urbana de Ibirataia superou a que vivia no campo. Foi no período de 1970 a 1980 que o município de Ibirataia mais cresceu (uma das fases áureas da cacauicultura), chegando a 2,8\% ao ano, com crescimento da população urbana e rural.

Analisando o crescimento médio anual intercensos, tem-se o seguinte quadro: crescimento populacional de 41,7\%, entre 1970 e 1991, e decréscimo da população da ordem de 23,2\%, entre os censos de 2000 e 2010, perdas de contingente populacional tanto na área urbana quanto rural. Entre 2000 e 2010, Ibirataia registrou um crescimento anual negativo de -2,63\%, já na Microrregião Itabuna-Ilhéus, o percentual foi de $7,40 \%$, isto porque $75 \%$ dos municípios da região apresentaram variação demográfica negativa no mesmo período. Apenas 10 municípios apresentaram variação demográfica positiva no período 2000/2010, a saber: Belmonte, Firmino Alves, Gandu, Ibirapitanga, Ipiaú, Itabuna, Itacaré, Ubatã, Teolândia e Camacan.

O Gráfico 1, apresenta a dinâmica populacional de Ibirataia e dos seus municípios limítrofes, entre as décadas de 1991 e 2010. Os dados dessa tabela informam perdas significativas de contingente populacional em todos os municípios ao longo do período analisado, e mesmo o município de Ipiaú, que registrou um crescimento positivo entre 2000/2010, não conseguiu retornar à sua população registrada em 1991. 
Gráfico 1 - Dinâmica populacional de Ibirataia e municípios limítrofes (1991-2010)

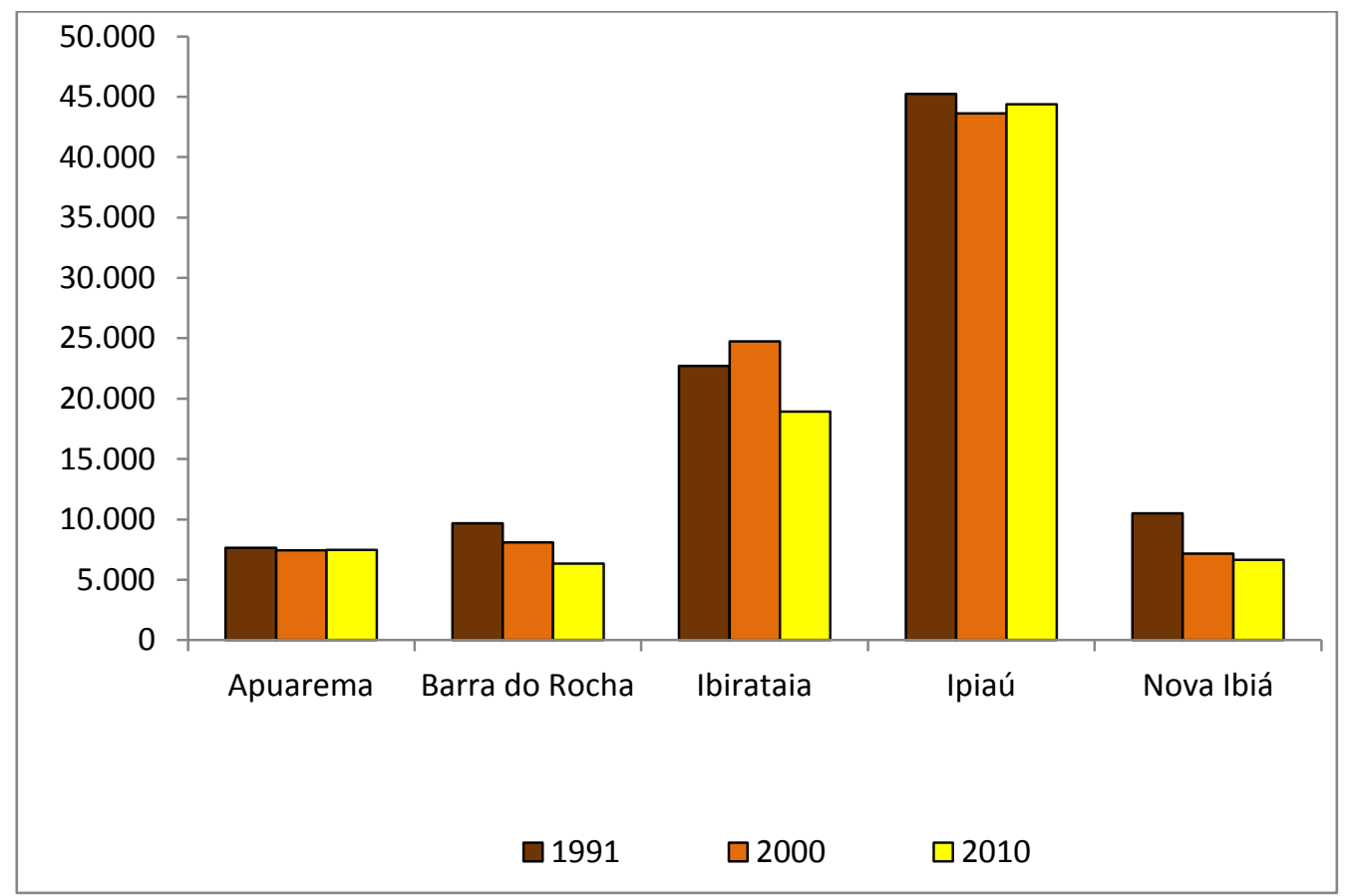

Fonte: Censos Demográficos, IBGE - 1991/2010. (Elaborado pelo autor)

Os dados contidos no gráfico indicam que entre os municípios apresentados, apenas Ibirataia teve crescimento positivo no decênio 2000 a 2010, evidenciando que mesmo numa área onde aparentemente os municípios têm realidades bastante parecidas, as idiossincrasias também precisam ser levadas em conta, sobretudo no que se refere aos aspectos do planejamento urbano.

Mais de $84 \%$ da população de Ibirataia se autodeclararam como negros ou pardos no último censo e pouco mais de $14 \%$ se autodeclararam como brancos - uma distribuição próxima da encontrada no conjunto da população da Microrregião ItabunaIlhéus (79,8\% negros ou pardos brancos e 18,2\% de brancos) e do Estado da Bahia (76,3\% negros ou pardos brancos e $22,2 \%$ de brancos). O número de habitantes autodeclarados amarelos somava menos de 1,0\% do total. Já a população indígena que, em 2000, somava $0,13 \%$ (33 habitantes), em 2010, passa a 0 (zero).

Quanto ao perfil etário, a comparação dos dois últimos censos mostra um sensível envelhecimento da população residente, com queda dos percentuais de crianças de 0 a 4 anos na população, adolescentes e adultos jovens até 24 anos, manutenção da parcela de adultos de 25 a 39 anos e um leve crescimento dos estratos acima de 50 anos ou mais de idade. Comparando-se os perfis de 2000 e 2010, nota-se tendência à diminuição das faixas mais jovens, uma vez que as famílias passaram a ter menos filhos e pela forte emigração da população jovem em idade de trabalho, que deixa o município 
em busca de oportunidade de emprego em outras localidades. Outra tendência é o envelhecimento da população.

Os indicadores populacionais de Ibirataia refletem de um lado o declínio da mortalidade infantil, sobretudo entre as crianças de 0-4 anos; e o envelhecimento da população. O Censo Demográfico do IBGE de 2010 revela que as faixas com maior representatividade são as de 10/14, 15/19 e 20/29 anos, esta última em plena idade de inserção no mercado de trabalho, o que reflete diretamente num acirramento por novos postos de trabalho. Por sua vez, a faixa mais idosa foi levemente ampliada, sinalizando um envelhecimento da população, principalmente entre as mulheres, que são mais numerosas. Em 2000, as mulheres de 70 anos ou mais eram cerca de 421, representando 3,38\% do total de mulheres. Em 2010, elas passaram para 708, passando a representar $7,82 \%$. No caso dos homens, ocorreu um decréscimo da população nessa faixa etária (Figuras 3 e 4), no ano 2000, eram 586, ou seja, 4,76\% enquanto no ano de 2010 esse número reduziu-se para 525, porém em termos percentuais subiu para 5,56\%. O conjunto dessas informações fornecem indícios das profundas alterações nas demandas sobre o sistema de saúde, o emprego, a seguridade social, entre outras.

\section{Considerações finais}

Ao se trabalhar com questões migratórias, com o objetivo de caracterizar o movimento populacional, é pertinente levar em consideração que não se discutirá apenas números e tabelas, mas, entrar em contato com uma gama de conjecturas que permeiam as relações sociais, ou seja, os movimentos migratórios trazem em si elementos fundamentais, sejam eles históricos, políticos, ou econômicos que podem auxiliar na compreensão dos rumos de uma sociedade.

Particularmente em Ibirataia, mesmo se tratando de uma localidade com uma pequena população, foi verificado que os fluxos migratórios que a envolveram e que ainda a envolve são capazes em grande parte de explicar e fomentar novas discussões acerca dos planos estratégicos que devem ser traçados, visando planejar a cidade para os próximos decênios, por exemplo, a partir do perfil migratório construído ao longo da história recente.

Um dos fios condutores desses fluxos migratórios envolvendo Ibirataia girou em torno da monocultura do cacau, seja como fator atrativo, auxiliando inclusive no processo de emancipação política do município, ou como fator repulsivo, considerando 
a crise da vassoura-de-bruxa no final da década de 1980, que levou milhares de pessoas a buscar melhores condições de vida em outros locais.

$\mathrm{O}$ estudo permitiu identificar elementos que justificassem ou pudessem caracterizar de forma mais fidedigna os motivos que deram origem a esses movimentos migratórios, nesse sentido, o papel exercido pelo cacau, refletiu a inter-relação de elementos do tempo e do espaço que permitem a construção de instrumentos capazes de pensar o futuro de Ibirataia e de sua população para os próximos anos.

As Figuras 3 e 4 que tratam particularmente da composição demográfica do município, analisa o perfil da população através das pirâmides etárias, na qual retrata uma transformação considerável na estrutura da pirâmide, ficando evidente a redução da taxa de natalidade e da composição de jovens no total da população, seguida de um leve aumento no número de idosos, o que exige a princípio uma reflexão sobre o "porquê" dessa transformação e também repensar a própria infra-estrutura urbana, como calçadas, ofertas de lazer, programas sociais, entre outros, para atender as possíveis demandas dessa nova realidade que se apresenta.

A Tabela 3 que trata da taxa de urbanização apresentada pelo município nos últimos anos, reforça a ideia de que é preciso construir um novo modelo de planejamento municipal, pois ao mesmo tempo em que apresenta uma taxa de urbanização crescente ano após ano, precisa também enfrentar o fato de que sua população tem reduzido basicamente na mesma proporção, fazendo com que Ibirataia se caracterize como uma cidade de forte repulsão populacional.

A condição que se estabelece, de perda no número total de habitantes, impacta negativamente na arrecadação do município, já que alguns repasses de verba são realizados a partir do número de habitantes da localidade, e a falta desse recurso compromete o investimento em áreas essências para o desenvolvimento de uma sociedade, tais como: saúde, educação e segurança.

Dessa forma, alargar a ideia que se tem com relação à questão demográfica de um município, somando-se a caracterização do espaço urbano local, bem como de sua rede urbana, pode contribuir para um melhor exercício dos padrões de governança, que vem obtendo nos últimos anos um destaque importante para distinguir, o papel da referida governança com suas respectivas funções, do papel exercido pela prática política.

Outra característica importante da análise das migrações em Ibirataia é o fato de que essa não é uma realidade específica da população local, ou seja, a grande maioria 
dos municípios que compunham a Região Cacaueira, tem apresentado realidades em alguns pontos semelhantes às de Ibirataia, o que leva a crer que deva se construir alternativas coletivas, visando beneficiar toda uma região.

Portanto ainda que os impactos decorrentes da crise da lavoura cacaueira e dos fluxos migratórios negativos, não atuem de forma direta, singular e homogênea e que não ocorram igualitariamente pelo território de Ibirataia e das cidades de sua microrregião. Ainda assim esses impactos podem interferir no processo de articulação dessas cidades, com as demais áreas do estado e do país, criando desafios sociais e econômicos diferenciados.

\section{Referências}

IBGE, 2000. Censo Demográfico de 2000. Instituto Brasileiro de Geografia e Estatística, dados referentes ao município de Ibirataia, disponível em: < http://www.cidades.ibge.gov.br/xtras/perfil.php?lang=\&codmun=291290> - Acesso em: 27 de Jul. de 2014.

IBGE, 2010. Censo Demográfico de 2010. Instituto Brasileiro de Geografia e Estatística, dados referentes ao município de Ibirataia, disponível em:

<http://www.cidades.ibge.gov.br/painel/historico.php?lang=\&codmun=291290\&search =bahia|ibirataia|infograficos:-historico > - acesso em: 27 de Jul. 2014

MENDES COSTA, Francisco. Políticas públicas e atores sociais na evolução da cacauicultura baiana. Vila Velha, ES: Opção Editora, 2012. 252 p.

MINISTÉRIO DA SAÚDE. Indicadores de mortalidade (página eletrônica). Disponível em: http://tabnet.datasus.gov.br/cgi/idb2000/fqc01.htm - acesso em: 10 de Fev. 2015.

OLIVEIRA, C. G. S. de; TRINDADE, G. A.; GRAMACHO, M. H. Trajetória, permanência e transformações têmporo-espaciais na cidade de Camacan/BA: interfaces com a crise da cacauicultura. Ilhéus: Editus, 2009.

ROCHA, Lurdes Bertol. O centro da cidade de Itabuna: trajetória, signos e significados, Ilhéus- BA: Editus, 2003.

SANTOS, A.A.P. Diagnósticos Municipais: Ibirataia. Salvador: Instituto Gaparetto, 2013. (Série Estudos e Pesquisas). 401p.

SANTOS, Alan Azevedo Pereira. Diagnóstico da Violência e Criminalidade em Itabuna-BA. Itabuna: Instituto-PROSEM, 2012. 140 p. Disponível em: <http://www.academia.edu/6239663/Diagn\%C3\%B3stico_da_Viol\%C3\%AAncia_e_Cr iminalidade_em_Itabuna_BA>. Acesso em: 10 de Jun. 2014. 
SANTOS, Maria Luiza Silva. Migração e pobreza no sul da bahia: A relação com a teoria da privação das capacidades, disponível em:

$<$ http://www.abep.nepo.unicamp.br/docs/anais/outros/6EncNacSobreMigracoes/ST1/M ariaLuizaSilva.pdf> - acesso em: 26 de Jun. 2014.

SANTOS, M.; SILVEIRA, M. L. O Brasil: território e sociedade no início do século XXI 10 ${ }^{\text {a }}$ Ed. - Rio de Janeiro: Record, 2008. 212 e 213 p.

SANTOS, Milton, SILVEIRA, M. L. O Brasil: território e sociedade no início do século XXI / Milton Santos, Maria Luiza Silveira - 5 a ed. - Rio de Janeiro: Record, 2003.

SCARLATO, F. C. população e urbanização brasileira. In: ROSS, J. (Orgs). Geografia do Brasil, São Paulo: Edusp, 1996.

TESOURAS NOTICIAS. Em: <http://www.tesourasnoticias.com.br/> - acesso em 30 de Jul. 2014.

TRINDADE, Gilmar Alves. Aglomeração Itabuna-Ilhéus: cidade, região e rede urbana (Tese de Doutorado). Universidade Federal de Sergipe, 2011.

Recebido em: 20/09/2017

Aceito para publicação em: 10/10/2017 